\title{
Estudo de caso da animação Sam's Story sobre a experiência de pessoas trans
}

Sam's Story animation case study on the experience of trans people

\author{
Maria Eduarda Becker Gorges \\ Universidade do Vale do Itajaí \\ dudabeckerg@gmail.com \\ X \\ Rafael Marques de Albuquerque \\ Universidade do Vale do Itajaí \\ albuquerque@univali.br \\ $\mathbf{X}$
}

\section{PROJËTICA}

\section{COMO CITAR ESTE ARTIGO:}

GORGES, Maria Eduarda Becker; ALBUQUERQUE, Rafael Marques de. Estudo de caso da animação Sam's Story sobre a experiência de pessoas trans. Projética, Londrina, v. 12, n. 1, p. 327-348, 2021

DOI: 10.5433/2236-2207.2021v12n1p327

Submissão: 19-06-2019

Aceite: 12-12-2019 
RESUMO: A representação de personagens trans na mídia mostra-se historicamente escassa. Mesmo para autores com intenção de ampliar o espectro de gênero na representação de seus personagens, representar adequadamente personagens trans pode ser desafiador, exigindo pesquisa e reflexão. O presente artigo descreve um estudo de caso sobre uma animação chamada Sam's Story, que aborda a temática trans, de forma a elucidar pontos de reflexão importantes. O objetivo do artigo é fomentar a reflexão crítica por parte de outros autores que queiram tornar suas obras mais diversas ao representar personagens trans. Foram analisados os cuidados para com um tema sensível como esse, assim como as metáforas utilizadas na animação, a tradução de experiências de vida de pessoas trans em cenas, a mensagem geral da animação e seu conteúdo artístico - visual e sonoro.

Palavras-chave:Animação2D.Tradigital.Transgênero.LGBTQ+. Representatividade. FTM.

ABSTRACT: The representation of trans characters in media is historically scarce. Even for authors who intend to expand the gender spectrum in their characters, a proper representation of trans people may be challenging, requiring research and reflection over the theme. This paper describes a case study about an animation called Sam's Story, which approaches the trans theme, in order to provoke important aspects for reflection. The objective is to encourage a critical reflection on authors who are willing to make their work more diverse by representing trans characters. We analyzed the metaphors used in the animation, the translation of life experiences of the trans people in the scenes, the overall message of the animation and its artistic content - both visual and sound.

Keywords: 2D animation. Tradigital. Transgender. LGBTQ+. Representativity. FTM. 


\section{INTRODUÇÃO}

Pessoas trans, ou seja, pessoas que não se identificam com o gênero que thes foi designado ao nascer, enfrentam diversas dificuldades em nossa sociedade, especialmente no Brasil, onde há um alto número de crimes transfóbicos no país (JESUS, 2013). As dificuldades enfrentadas por esse grupo são várias: a ocorrência de bullying, exclusão no ambiente escolar e expulsão de adolescentes das famílias, a falta de escolaridade (que pode decorrer do abandono escolar), a dificuldade em conseguir empregos devido ao preconceito, a agressão física e verbal, e consequentemente, o elevado nível de suicídio.

Um dos mecanismos que pode trazer um contraponto e construir outras narrativas e significados para a questão trans é a mídia: possivelmente trazendo conforto, conscientização e visão crítica sobre essas questões. Entre elas, as animações (também conhecidas como desenhos animados) são expressões da arte e que podem carregar junto a si vários sentimentos, de forma a tocar a audiência tanto por meio de informações quanto por seu apelo emocional.

De forma a aproveitar esse potencial das animações, os autores analisaram uma animação para apoio e conscientização, visando transmitir ao público empatia para com as pessoas transgênero, para que provoque emoção ao mostrar um pouco de sua experiência e problemas que enfrentam. Além de importante para a comunidade trans, a animação parece ter o potencial de ajudar a comunidade cis gênero (ou seja, as pessoas que se identificam com o gênero designado a elas ao nascer) a refletir sobre o quanto a transfobia é um construto social destrutivo, sugerindo ao público reflexões sobre sua visão de mundo.

Em casos como esse, é necessário que haja atenção redobrada por meio do autor ou desenvolvedor, afinal animações são grandes influenciadoras de expressão, e ao envolver um assunto tão delicado, o descuido pode servir como 
gatilho para pensamentos negativos, ou reforçar preconceitos que se pretendia combater. Um problema de representação - que pode soar como um detalhe para alguém alheio a determinadas questões delicadas - pode ser a diferença entre a aceitação da comunidade trans para com a animação, sua rejeição ou até o repúdio.

Por isso, no decorrer deste artigo será discutido sobre as decisões da arte, história, o tema sobre a comunidade transgênero e a cautela tomada com o público. A discussão do presente artigo se dará por cima da animação Sam's Story em um estudo de caso, visando explicitar pontos importantes de reflexão sobre a obra. $\mathrm{O}$ objetivo é fomentar a discussão e reflexão de outros autores e desenvolvedores que também queiram abordar a tão importante temática. A animação pode ser acessada gratuitamente em plataformas online como YouTube ${ }^{1}$.

\section{FUNDAMENTAÇÃO TEÓRICA}

\subsection{A questão Trans - Gênero, Cis(hetero)normatividade e a Teoria Queer}

Para discussão do trabalho analisado, foi necessária a busca por esclarecimentos sobre os termos e conceitos da área, já que um assunto delicado como a transgeneridade pode gerar discussões e desentendimentos, até casos mais extremos como a generalização, preconceito e ofensa.

Diferentemente do que muita gente imagina, o ser humano possui uma rica variedade de identidades, não só o que é evidente na questão fisiológica, como a distinção de homem e mulher como sexos. O que os estudos de gênero têm mostrado é que, quando são comparadas as questões biológicas com as questões culturais, sociais e psicológicas, elas não são necessariamente condizentes umas com as outras. Embora não seja a única interpretação nos estudos de gênero,

[1] Para este trabalho, a animação foi acessada no endereço https://www.youtube. com/watch?v=OyZPId4VVnM em junho de 2019, com o título Sam's Story do canal The You Inside /

Au Coeur de toi. 
autores como Souza e Araújo (2017) pontuam que o sexo é biológico, enquanto gênero e sexualidade são culturalmente construídos.

Em termos de gênero, os seres humanos podem ser enquadrados, basicamente, como transgênero ou cisgênero. Cis gênero, ou "cis", são as pessoas que se identificam com o gênero que Ihes foi atribuído no nascimento (homem ou mulher, com exceções). Já transgênero são as pessoas cuja identidade de gênero, expressão ou comportamento é diferente dos que tipicamente são associados com seu sexo atribuído no nascimento, ou seja, ela pode não se identificar com o sexo atribuído a ela ao nascer (JESUS, 2012).

Como um grande leque de sentidos está contido no gênero Trans, podese dividi-lo em duas descrições diferentes, considerando a expressão de vivência humana (JESUS, 2012):

1. Identidade (o que caracteriza, por exemplo, transexuais e travestis);

2. Expressão (representado por crossdressers, drag queens, drag kings, assim como pessoas andróginas, homens afeminados e mulheres masculinizadas, etc).

As pessoas na segunda categoria não têm necessariamente nenhuma condição transgênera, ou seja, não tenham discordância com o seu sexo atribuído ao nascer. Somente a sua expressão de gênero, a forma pela qual expressam seu gênero (aparência, voz), que transgride o papel de gênero socialmente esperado dele. Esses casos diferem quando há uma identidade de gênero trans, que é associada com a forma como se sentem e reconhecem como pessoa (HILL; MAYS, 2014).

Um exemplo de expressão relacionada com essa discussão são as drags, cuja definição é de serem uma forma de entretenimento; artistas que interpretam 
personagens por meio de sua vestimenta e performance. Quando a diferença entre drag e transexual não é devidamente compreendida, a confusão pode fazer com que equivocadamente se associe a identidade trans com apenas um show que eles estejam simulando, em vez de uma característica identitária mais profunda (James, S. E., Jackson, T., \& Jim, M. (2017).

As pessoas transexuais por vezes se sentem presas a um corpo no qual não sente ser o adequado, principalmente pela forma como pensam e se sentem. As mudanças na forma de expressar-se podem ser variadas, como vestimenta e corte de cabelo, ou como mudanças com o corpo, em tratamentos hormonais e procedimentos cirúrgicos para uma possível redesignação de sexo. Vale ressaltar que para muitos transexuais, é de grande importância viver sua identidade como um todo: além da estética para ser reconhecido como o seu gênero, ser aceito social e profissionalmente com o nome pelo qual se identifica. Assim como poder usar o banheiro correspondente à sua identidade de gênero, sem ter problemas em se sentir desconfortável por não estar sendo aceito ali, entre outros contextos sociais. Porém a "interferência" social pode o bloquear na adequação, por medo de ser agredido, desabrigado, ou algo pior. Ocorrendo uma grande repressão em poder se expressar, viver sua identidade trans, influenciando em seu estado psicológico (AMV Terra, A SCHREIBER, CN KONDER, 2016). Pode-ser argumentar que o sofrimento das pessoas trans é, antes de qualquer outra coisa, gerado pela sociedade cuja transfobia impede uma aceitação mais ampla de sua identidade.

Para identificar as pessoas trans que passam por transição na expressão de gênero, pode-se utilizar FTM para pessoas que transicionam de feminino para masculino (female to male), ou seja, o sexo atribuído no nascimento é mulher, mas é um homem e assim se identifica. Também conhecido como um homem transgênero, homem transexual, ou apenas homem trans. Ou MTF para pessoas que transicionam de masculino para feminino (male to female), cuja atribuição no 
nascimento foi como homem, mas que é mulher e assi se identifica. Conhecido como mulher transgênero.

Desde a antiguidade a sociedade é regida por normas sociais sobre o que é ser homem e o que é ser mulher, aprendendo quais são os papéis de cada um desde a infância, por meio de cores, brinquedos, roupas, comportamento, etc. Pode-se perceber a reprodução desses valores sexistas em diversas ocasiões, como por exemplo em um casal de mulheres, a qual muitas vezes questiona-se qual delas é o "homem" da relação, ou na composição da família, quando a mulher solteira é cobrada para arranjar um parceiro e possivelmente garantir um pai para a criança. $O$ avanço nos estudos de gênero e movimentos feministas estão contribuindo para que, aos poucos, haja a quebra desse padrão. Butler (2016) defende sua teoria (Queer) sobre os não-binários que rejeitam as atribuições binárias determinadas pela sociedade, o "ser homem" e o "ser mulher", desafiando a ordem heterossexual como sinônimo de normalidade.

E ao ser questionada em uma entrevista sobre a assimilação de gênero e biologia na Teoria Queer, Judith Butler (2016) respondeu em uma palestra, como relatado por Castilho (2015):

Há entre o homem e a mulher diferenças hormonais, fisiológicas, nos cromossomos. Mas embora trabalhemos com pensamento binário há variações, um continuum entre um e outro. Pesquisas revelam que biologia não é determinação, que o gênero resulta de uma combinação única, em cada um de nós, de fatores biológicos, sexuais, de função social, do auto-entendimento, da representação de gênero. Descobriuse que os hormônios são interativos e há várias maneiras em que podem ser ativados. Inclusive o desenvolvimento dos neurônios está ligado ao ambiente. $\mathrm{O}$ que acontece depende em parte da vida que se vive.

Visando toda essa descrença sobre diferentes identidades e de haver uma variedade mais complexa do que apenas homem e mulher, se mostra necessário 
que a discussão seja colocada em evidência e profundamente trabalhada, visando uma desconstrução e ampliação do que se considera feminino e masculino.

Como dito por Fabretti e Lima (2016, p. 2)

Os avanços nos estudos de gênero foram fundamentais para solidificar a concepção de que as diferenças biológicas entre os sexos não são responsáveis pelas desigualdades entre homens e mulheres. Constatar que essas diferenças são, na verdade, construções sociais legitimadas por uma sociedade patriarcal é uma contribuição fundamental dos estudos de gênero e do movimento feminista.

Para melhor entendê-la, poder-se-ia levar em conta a frase “Ela(e) usa o que quiser". Seus ideais consideram essa desconstrução do que é feminino e masculino, rompendo conceitos normatizadores e formas de vida (pré) estabelecidas. Aquilo que é estranho para muitos, pode ser o correto e libertador para outros, possibilitando a construção de uma identidade própria por meio da livre expressão, alargando a representatividade da diversidade humana.

Por mais que haja toda essa desconstrução e livre arbítrio de gêneros, a ideia dos sexos homem e mulher ainda permanece. E para o progresso desse movimento, são importantes os estudos acadêmicos, para que contribua nessa problematização sobre as novas construções de gênero em uma perspectiva emancipatória e de caráter pluralista. A aceitação das diferenças seria muito maior, diminuindo o nível alarmante de violência contra a comunidade.

\subsection{Animação e a Representação LGBTQ+ nas Mídias}

A comunidade LGBTQ+ está cada vez mais ganhando espaço na mídia, ainda mais percebido como um grande público consumidor, o chamado "pink money". E isso faz com que muitas empresas busquem expandir seus negócios ao oferecer produtos 
a essa comunidade, sem ao menos serem, de fato, apoiadoras. Assim, ao analisar personagens de filmes, novelas, animações e jogos, muitos personagens não tem sua história bem trabalhada, e são representados por meio de estereótipos. Como apontam Machado, Albuquerque e Alves (2018), a representação diversa é, no entanto, um desafio e uma responsabilidade para designers, e exige grande cuidado e profunda reflexão que envolvem não apenas questões de representação estética e visual, mas questões éticas, políticas, narrativas e filosóficas. Além disso, no caso de objetos complexos como jogos ou animações, abrangem diversas áreas de análise e estudo, como cita Albuquerque (2019, p. 4): “os problemas de representação - tanto LGBTQ+, de mulheres, pessoas com deficiência, etc. abrangem várias questões envolvendo aparência, arco narrativo, juízo de valor sobre os atributos do personagem, visibilidade e outras questões". É nesse sentido que mostram-se necessários estudos como o presente, que possam ajudar a reflexão dos conhecimentos sobre a complexidade da questão trans aplicada em um contexto de produção audiovisual.

\section{METODOLOGIA}

O presente artigo trata-se de uma pesquisa descritiva, que utiliza o método de estudo de caso com Sam's Story, e tem como propósito mostrar a escolha feita pelo autor em trabalhar seu conteúdo, e a importância da cautela na aplicação do mesmo, já que é necessária para o desenvolvimento de temáticas delicadas. Partindo de uma revisão bibliográfica, foi adquirido mais conhecimento sobre o assunto com a função de posteriormente oferecer informação ao público. O objetivo de analisar a animação é complementar as visões e propostas de produto, de forma a gerar reflexões complementares.

Para isso, foram definidos os seguintes tópicos para análise: cuidados com o tema, a representação por metáfora, a representação das experiências no roteiro, a mensagem da animação e a manifestação artística do conteúdo. Os resultados 
obtidos mediante a análise servirão de auxílio para que autores e desenvolvedores, ao trabalharem em estudos similares, possam ter referências empíricas que dialoguem com a teoria.

\section{AS ANIMAÇÕES ANALISADAS}

\subsection{Sam's Story}

Sam's story é uma animação 2D (bidimensional) sobre um menino trans, e como parte de um projeto, tornaram este personagem um boneco estilo "Russian Doll", sendo cada tamanho uma fase diferente de Sam (SAM'S ..., 2017). A ação foi promovida pelo grupo Gender Creative Kids Canada no KickStarter, com o intuito de entreter crianças de uma forma educativa e que possam entender um pouco dos sentimentos de Sam.

Figura 1 - Boneco Sam.

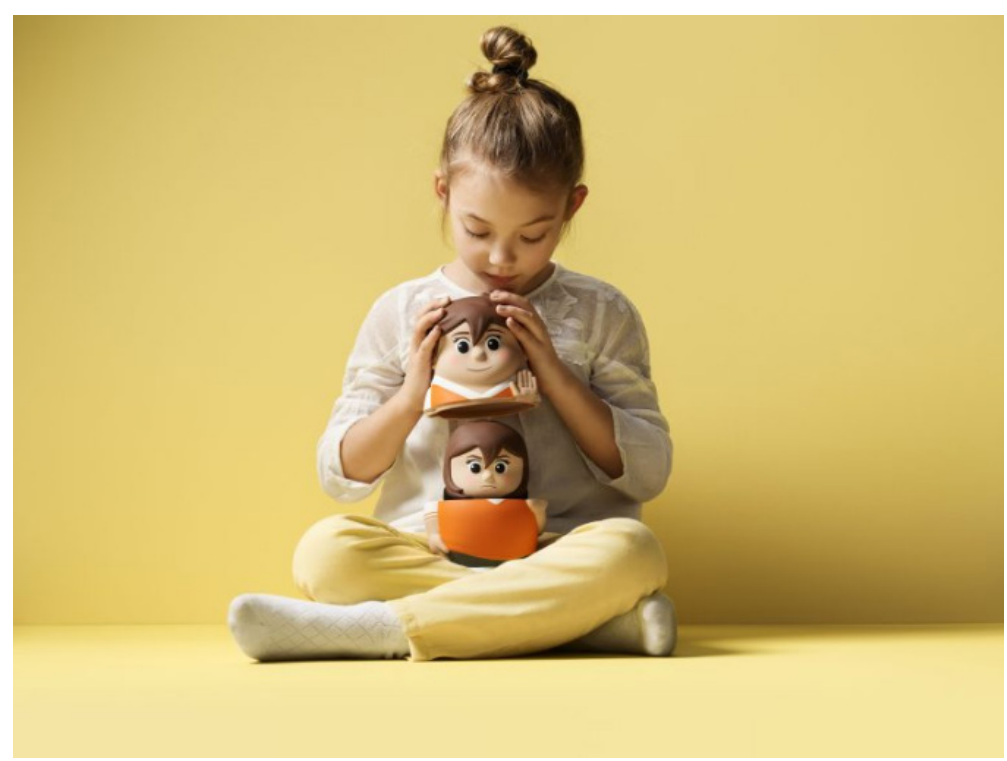

Fonte: Gender Creative Kids Canada (2018). 
Há entre o homem e a mulher diferenças hormonais, fisiológicas, nos cromossomos. Mas embora trabalhemos com pensamento binário há variações, um continuum entre um e outro. Pesquisas revelam que biologia não é determinação, que o gênero resulta de uma combinação única, em cada um de nós, de fatores biológicos, sexuais, de função social, do auto-entendimento, da representação de gênero. Descobriu-se que os hormônios são interativos e há várias maneiras em que podem ser ativados. Inclusive o desenvolvimento dos neurônios está ligado ao ambiente. O que acontece depende em parte da vida que se vive.

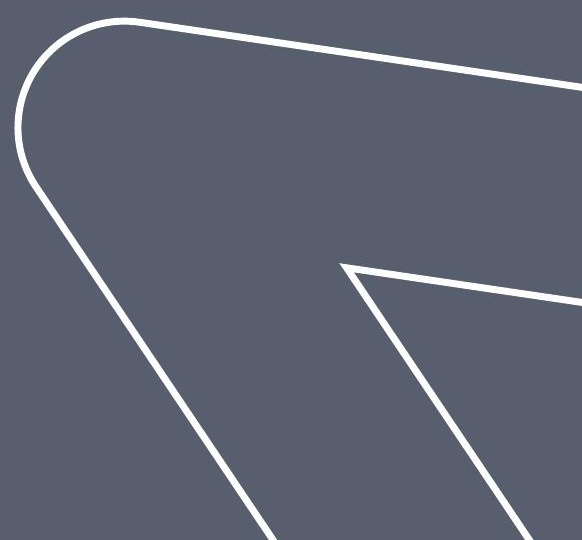


Sua história é mostrada desde bebê, por meio de etapas da vida. E cada etapa representa um sentimento que ele sente, através das experiências com o mundo em detrimento a si próprio. Mas não apenas isso, o seu Eu interior é representado com um irmão gêmeo do sexo oposto. Então após anos não se sentindo aceito pela família e pelas outras crianças, Sam se isola de todos. E quando seus pais finalmente entendem seus sentimentos, eles o aceitam e o menino, que agora ele e seu "gêmeo" se tornam um só, vive sua vida livre dos padrões que antes eram tão estabelecidos.

Figura 2 - Cena da animação Sam's Story.

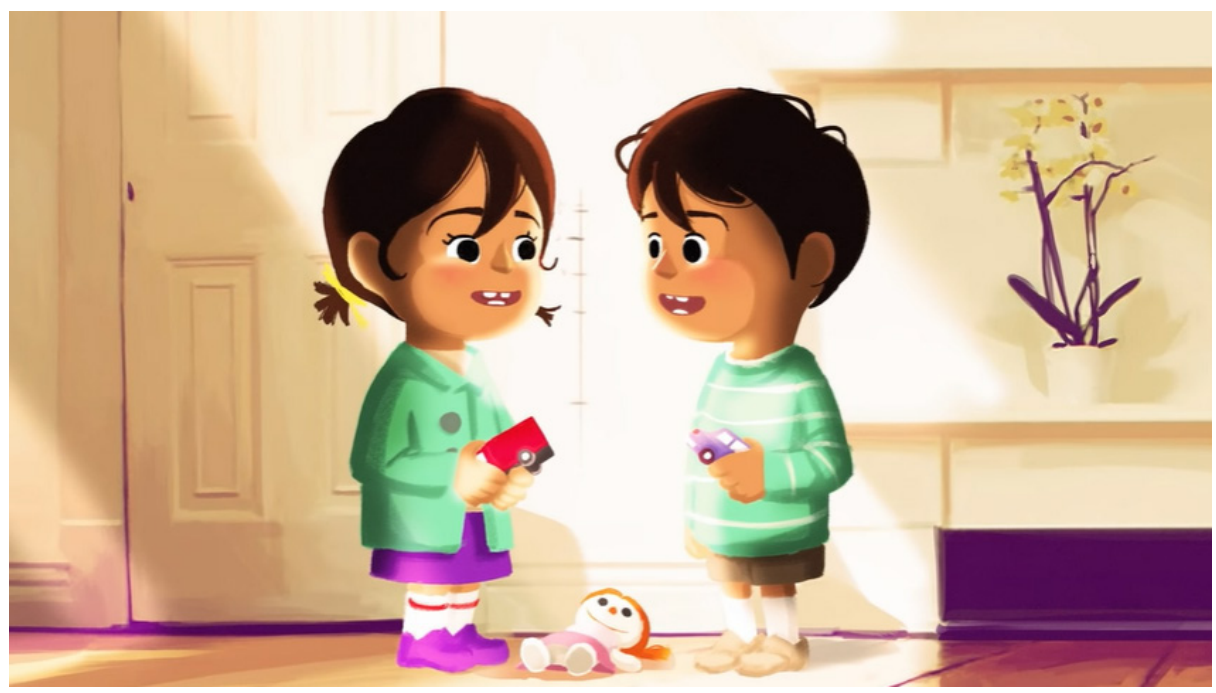

Fonte: Sam's... (2017).

\section{DISCUSSÃO E ANÁLISE}

\subsection{Cuidados com o Tema}

Um dos fatores mais importantes que se deve levar em consideração é a precaução de como passar o conteúdo, pois dependendo do que possa conter na história e 
como ele é reproduzido, pode engatilhar más lembranças e sentimentos difíceis para algumas pessoas.

No caso de Sam's Story em específico, parte de sua audiência é infantil, pois é o público-alvo de seu projeto. Provavelmente esse fator influenciou na decisão de não mostrar violência gráfica, e sim mostrar dilemas de aceitação. Há algumas questões complexas na representação de grupos cujo tratamento dado pela sociedade é tão cruel, como a comunidade trans. Por um lado, há uma necessidade de denúncia e sensibilização para as diversas formas de discriminação. Por outro, é importante criar representações midiáticas que ressignifiquem as possibilidades de vivência e desfecho trans. Nesse sentido, é necessário pensar em representações que nem caiam na ingenuidade de negar ou subestimar a seriedade da transfobia, nem representem apenas a pessoa trans como vítima. Pode-se pensar em representações cujas mensagens transgridam com as expectativas do espectador, criando narrativas alternativas sobre temas conhecidos. Em Sam's Story há uma mescla do drama da vivência trans com um final feliz de forma inesperada; pela possibilidade de unificar os dois Sam's em um só.

\subsection{Representação por Metáfora}

Em Sam's Story, a história é representada por meio de duas crianças de sexo oposto, e com subjetividade, podem ser interpretadas como gêmeos. Porém, conforme a história avança, fica mais evidente que ao invés de gêmeos, é apenas uma criança e seu Eu interior sendo representado.

A metáfora possui o poder de dar distanciamento entre o espectador e o que é representado, de forma que ele possa desenvolver um novo olhar sobre o tema (MACHADO; ALBUQUERQUE; ALVES, 2018). Portanto, metáforas podem ser 
ferramentas poderosas para renovar o olhar do espectador sobre um assunto que ele acredita conhecer, como a própria noção de gênero.

Nesse caso, a representação de gênero na animação é dada metaforicamente pela presença da criança de sexo oposto. E o uso de metáforas auxilia no modo que a temática será expressada, pois pode ser relacionado de uma forma mais leve ou profunda, de certa forma enigmática, já que o espectador deve interpretar a analogia, e esta tem o poder de surpreendê-lo. Como sugere O'Connor e Seymour (1995, p. 135) “Uma metáfora contada de maneira clara e simples distrai a mente consciente e ativa a procura inconsciente por significados e recursos".

Em um dos momentos mais importantes da obra, os dois "irmãos gêmeos" ficam lado a lado, quando percebemos que eles são iguais. Em seguida, eles se unem, formando um só. Essa metáfora torna-se potente por representar uma forma de integração da pessoa, onde o conflito interno entre as duas identidades resolve-se em harmonia. A partir do momento que as pessoas percebem a identidade masculina de Sam, o conflito interno entre os dois "eus" cessa. A representação gráfica da união dos dois gêmeos e do fato de eles serem idênticos possui o potencial de comunicar poeticamente essa mensagem de forma a unir ideia, emoção e visão de mundo.

\subsection{A Representação das Experiências no Roteiro}

Assim como humanos passam por fases na vida, Sam passa por dificuldades e alívios que são representadas ao longo das cenas. As experiências são retratadas como sentimentos em cada fase de sua vida. Em toda a infância, a inocência de Sam o liberta de preocupações e o peso do que gênero possa significar. Tanto a 
felicidade de um bebê, quanto a de uma criança que explora sua identidade através da brincadeira.

No entanto, ao dar passos no caminho do amadurecimento, Sam sente o impacto das normas culturalmente construídas em cima do gênero. Nem na simples prática de esporte Sam pode se divertir, sem que as crianças o excluam por ser do sexo oposto. Então ele começa a se questionar em como ele se encaixa - ou não - em tais normas, gerando conflitos constantes entre seus sentimentos e as expectativas da sociedade.

Até que ele experimenta cortar o cabelo, mas gera um resultado que o reprime ainda mais chegando ao ponto de não poder mais se expressar e tentar se adaptar de acordo com suas necessidades e sentimentos. E todo esse conflito faz com que Sam se isole dos colegas e da família, sentindo a nostalgia dos anos de inocência, quando brincava livremente sem sentir que era errado. Mas finalmente, depois dos pais entenderem o que ele estava sentindo, ele se sente aceito e apoiado da maneira como ele realmente é e expressa sua identidade.

O que pode-se notar é que, tanto as experiências, quanto os sentimentos, são comuns na comunidade trans. De certa forma, é como se a animação utilizasse experiências relatadas por pessoas trans - a disforia de gênero, a expulsão, o isolamento social - e retratassem essas experiências, mesmo que reinventadas dentro de um contexto metafórico. É necessário estudo e reflexão para a representações dessas experiências. Como coloca Albuquerque (2019, p. 5),

[...] se queremos contar uma história e criar personagens que sejam diversos e quebrem com os clichês, são necessários pesquisa, humildade e uma exploração que extrapole o senso comum. Acima de tudo, tenha sempre muito cuidado e respeito com a representação, especialmente se você estiver representando uma vivência que não é a sua. 
Tais representações podem ser importantes tanto para pessoas trans, quanto para pessoas cis. Uma representação midiática e poética de uma experiência pode ajudar a compreendê-la melhor, ampliando a capacidade do sujeito de construir significado a partir de sua própria experiência. Para a compreensão do que se vivencia, é necessário um repertório de experiências para as quais foi atribuído significado, e a ficção pode ajudar na constituição desse repertório emocional.

\subsection{A mensagem da Animação}

Levando em conta que pode ser a realidade de muitas pessoas, as experiências vividas pelo personagem puderam ser transmitidas e gerar uma representação com o conjunto da obra. E para que a ideia de transmitir apoio à comunidade possa ser mais bem incorporada, o grupo Gender Creative Kids Canada resolveu incorporar o incentivo por meio de um brinquedo: o personagem se tornou físico, e cada fase de sua vida, representando os sentimentos mencionados, teve sua versão no estilo "Russian Doll". A importância da ação é que a criança tenha um brinquedo educativo, e com incentivo dos pais, entenda os sentimentos de Sam. Ao final da animação, é dada a seguinte mensagem ao público "For a transgender child It's hard to make people see the you inside, but we can help to make it easier."2

É importante para o roteirista que ele tenha clareza sobre qual será sua mensagem, que pode ou não ser reforçada ao final da animação. De certa forma, o roteirista deve ter algo a dizer, e o audiovisual é apenas a linguagem para a transmissão de sua verdade de forma profunda, mesclando razão e emoção em uma experiência unificada (MCKEE, 2006). Dessa forma, a animação transmite alguma ideia autoral sobre um assunto, ou seja, no fundo há um conceito e uma perspectiva sobre o tema.

2 “Para uma criança transgênero é difícil de fazer as pessoas verem seu Eu interior, mas nós podemos ajudar a tornar isso mais fácil." (GENDER CREATIVE KIDS CANADA, 2018, tradução nossa). 


\subsection{A Manifestação Artística}

Para que um trabalho visual consiga expressar emoções ao público, alguns pontos são necessários para que isso aconteça. O áudio, o visual e a narrativa são grandes fontes de expressão, mas precisa ser muito bem trabalhado e escolhido para que isso aconteça. Não é qualquer tipo de arte, música ou história que consiga fazer isso.

Como a trama envolve o espectador emitindo muita emoção, deve haver um "casamento" entre esses meios de expressão da animação. E para que haja harmonia entre eles, é necessário destacar seus pontos de expressão, o que transmitem. Se por exemplo o seu objetivo é que o espectador sinta emoção com o trabalho, cuja palavra-chave seja positiva como esperança, a composição da música deve ser algo leve.

Figura 3 - Cena da animação

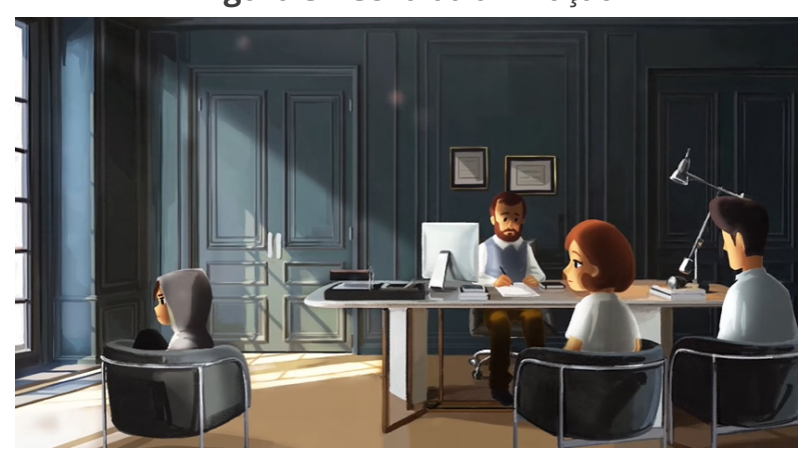

Fonte: Sam's... (2017).

Em Sam's Story tiveram um cuidado especial em deixar a animação leve, pois o personagem teve seu final feliz e nenhuma cena brusca, ou seja, que seja tão impactante para o espectador, que possa chegar a um ponto de engatilhar memórias ruins. A arte utiliza muita luz e partículas, transmitindo pureza, porém em alguns momentos de sentimentos negativos também são transmitidos pela falta dessa luz em parte do cenário, como pode ser visto na figura 3. 
As cores muitas vezes apresentam um granulado (Figura 4), o que causam a impressão de terem sido desenhados com alguma técnica manual como o giz de cera ou similar, muito usado por crianças. De certa forma, a animação parece dar vida a um desenho que, embora tenha a sofisticação da arte adulta, remete aos desenhos infantis. Dessa forma, os autores relacionam seu produto diretamente com o universo do público-alvo.

Figura 4 - Detalhe para as cores granuladas

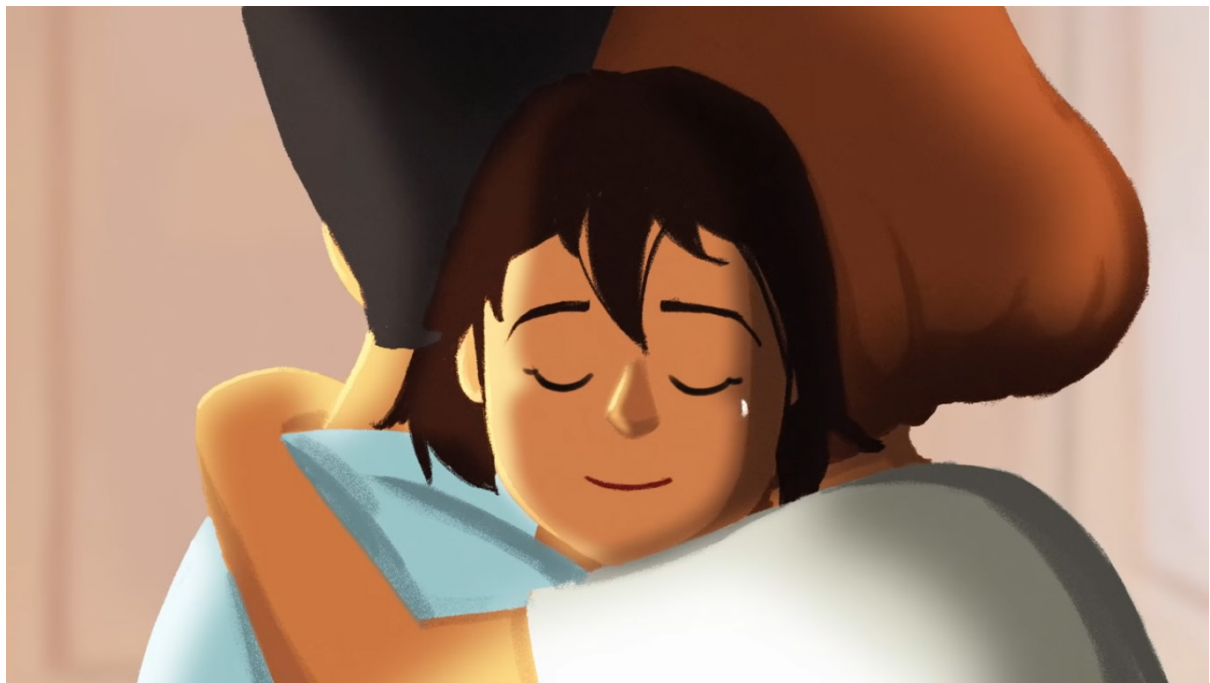

Fonte: Sam's... (2017).

Já sobre o fato da animação ter poucos frames de movimento - não ter realismo de movimento e tempo nas ações -, possibilita ao artista que haja mais qualidade no trabalho, podendo caprichar ainda mais em seu detalhamento.

\section{CONSIDERAÇÕES FINAIS}

A animação analisada possui o cunho de apoio à comunidade trans e LGBTQ+, seja dando visibilidade com sua representação, a história sendo finalizada com 
aceitação da família e que possa transmitir esperança, e até a mensagem final onde o autor transmite o que deseja passar através de dizeres ao público.

Esperamos que os pontos discutidos no presente artigo possam servir como auxílio para outros autores e/ou desenvolvedores que queiram trabalhar com materiais similares. Os tópicos separados para análise são de muita importância ao expressar a vivência de um personagem, já que possuem o peso de ter cuidado em como fazê-la e na riqueza de transmitir uma história por meio de uma figura de linguagem como a metáfora.

Por se tratar da análise de uma única animação, sem muita informação adicional, tornou-se mais limitado o aprofundamento nas discussões, e portanto, é necessário que haja mais discussões sobre a temática e os aspectos que podem ser trabalhados em cima. Pois apenas uma curta-metragem para análise é insuficiente para proporcionar uma boa base de auxílio para autores, e abre a possibilidade de coletar mais obras para serem discutidas com acréscimo de tópicos, e tornar o material completo como guia de estudos e desenvolvimento. 
Projética, Londrina, v. 12, n. 1, p. 327-348, março 2021

\section{REFERÊNCIAS}

1. AMV Terra, A SCHREIBER, CN KONDER. Direito Civil Constitucional. São Paulo: Atlas, 2016

2. ALBUQUERQUE, Rafael Marques de. Questões de gênero e orientação sexual na indústria dos jogos digitais. In: ALBUQUERQUE, Rafael Marques. Estudos contemporâneos em design de jogos e entretenimento digital. Florianópolis: Sagah, 2019. p. 5.

3. BUTLER, Judith. Problemas de gênero: feminismo e subversão da identidade. 11. ed. Tradução de Renato Aguiar. Rio de Janeiro: Civilização Brasileira, 2016.

4. FABRETTI, Irene Teresa Vieira; LIMA, Andréa Moreira. Teoria Queer: Desconstrução do paradigma binário de gênero. In: ENCONTRO REGIONAL DA ABRAPSO MINAS, 20., 2016, São João del-Rei, MG. Anais eletrônicos [...]. Disponível em: http://www.encontro2016.minas.abrapso.org.br/resources/ anais/18/1483719465_ARQUIVO_TrabalhoCompleto-Abrapso-PDF.pdf. Acesso em: 10 nov. 2018.

5. GENDER CREATIVE KIDS CANADA. Stopping transphobia before it starts. 2018. Disponível em: https://gendercreativekids.ca/stopping-transphobiabefore-it-starts/. Acesso em: 15 jun. 2019

6. HILL, Mel Reiff; MAYS, Jay. The gender book. Houston: Marshall House Press, 2014.

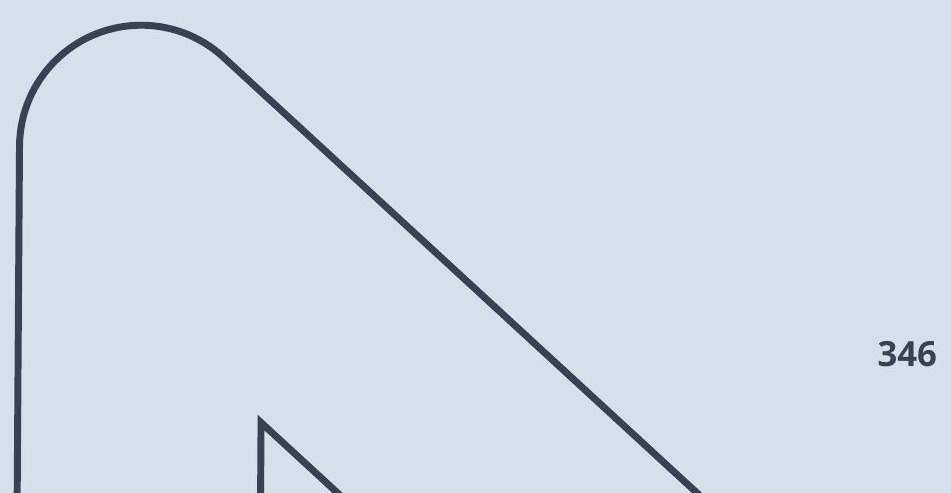




\section{Estudo de caso da animação Sam's Story... trans}

GORGES, M. E. B.; ALBUQUERQUE, R. M. de

7. James, Sandy; Jackson, Trudie; Jim, Mattee. 2015 U.S. Transgender Survey: Report on the Experiences of American Indian and Alaska Native Respondents . Washington, DC: National Center for Transgender Equality, 2017.

8. JESUS, Jaqueline Gomes de. Orientações sobre identidade de gênero: conceitos e termos. 2012. Brasília: Autor, 2012. Guia técnico sobre pessoas transexuais, travestis e demais transgêneros, para formadores de opinião. Disponível em: https://www.sertao.ufg.br/up/16/o/ORIENTA\%C3\%87\%C3\%95ES_ POPULA\%C3\%87\%C3\%830_TRANS.pdf?1334065989. Acesso em: 14 out. 2018.

9. JESUS, Jaqueline Gomes de. Transfobia e crimes de ódio: assassinatos de pessoas transgênero como genocídio. In: MARANHÃO FILHO, Eduardo Meinberg de Albuquerque (org.). (In)Visibilidade Trans 2. História Agora, a Revista de História do Tempo Presente, Santa Maria, RS, v.16, n. 2, p. 101-123, 2013. Disponível em: http://jaquejesus.blogspot.com/2015/08/transfobia-ecrimes-de-odio.html Acesso em: 11 nov. 2018.

10. MACHADO, Diego Domingos; ALBUQUERQUE, Rafael Marques; ALVES, Adriana Gomes. Problemáticas envolvendo raça, gênero e orientação sexual no desenvolvimento de jogos: relato de experiência com o jogo Trevo. Conexão - Comunicação e Cultura, Caxias do Sul, RS, v. 17, n. 34, p. 279-305, jul./dez. 2018.

11. MCKEE, Robert. Story: substância, estrutura, estilo e os princípios da escrita de roteiros. Curitiba, PR: Arte \& Letra, 2006. 
Projética, Londrina, v. 12, n. 1, p. 327-348, março 2021

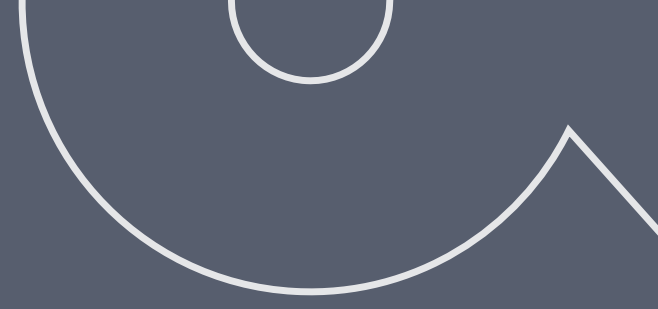

12. O'CONNOR, Joseph; SEYMOUR, John. Introdução à programação neurolingüística: como entender e influenciar as pessoas. São Paulo, SP: Summus Editorial, 1995.

13. SAM's story. [S. I.: s. n.], 2017. 1 vídeo (4:15 min). Publicado por The You Inside / Au Coeur de Toi. Disponível em: https://youtu.be/OyZPId4VVnM. Acesso em: 14 jun. 2019.

14. SOUZA, Ravelli Henrique de; ARAÚJO, Karina de Toledo. Gênero na escola: quebrando a barreira da homogenização das diferenças. In: CONGRESSO NORTE PARANAENSE DE EDUCAÇÃO FíSICA ESCOLAR, 8., 2017, Londrina, PR. Anais eletrônicos [...]. Londrina: Universidade Estadual de Londrina, 2017. Disponível em: http://www.uel.br/eventos/conpef/portal/pages/arquivos/ ANAIS\%20CONPEF\%202017/genero\%20na\%20escola\%20128597-19775.pdf. Acesso em: 10 nov. 2018.

15. WILLIAMS, Richard. Manual de animação. Tradução de Leandro de Mello Guimarães. São Paulo: Senac, 2016.

16. WINDER, Catherine; DOWLATABADI, Zahra. Producing animation. 2. ed. Waltham: Focal Press, 2011.
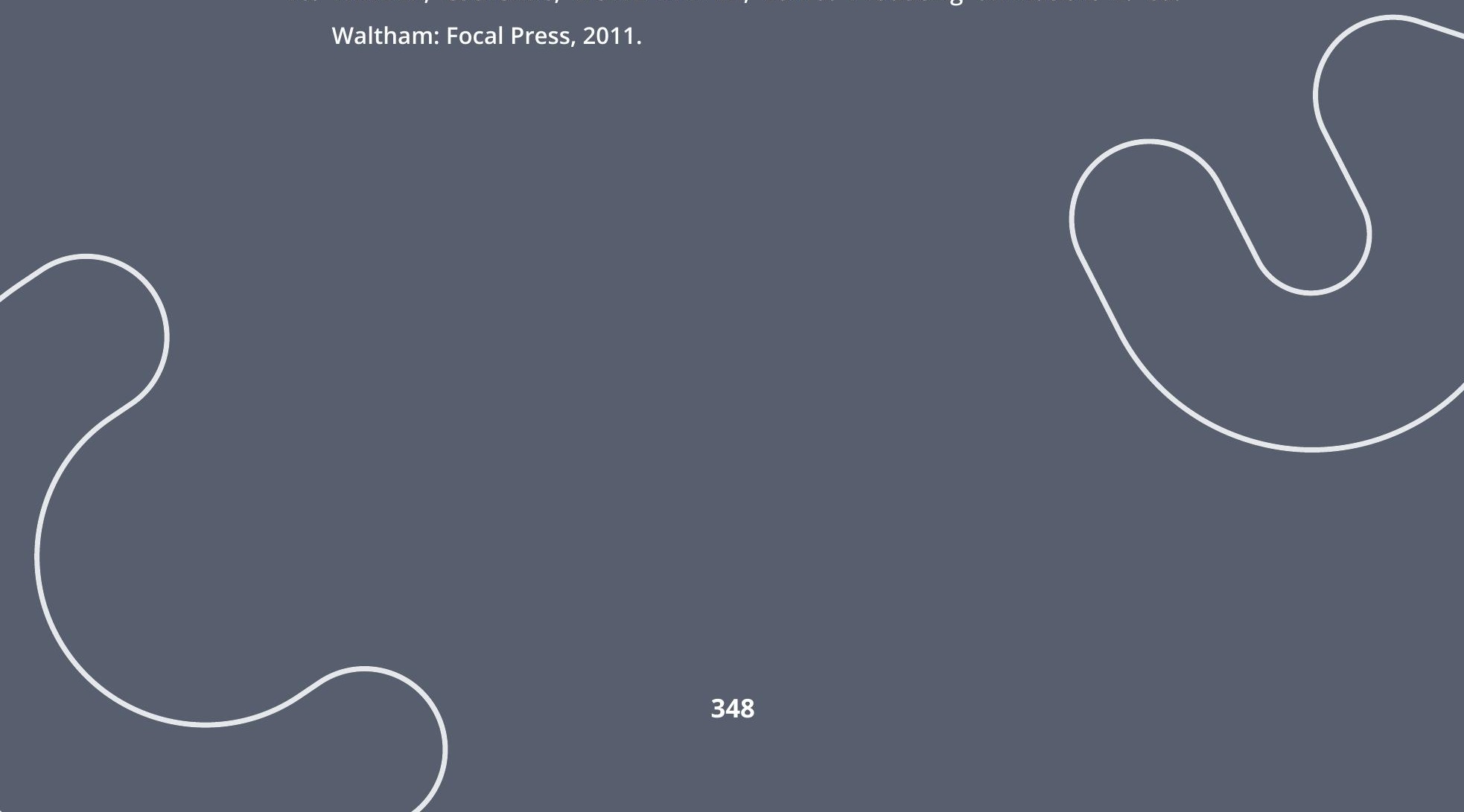